\title{
Game On: The Rise of the eSports Middle Kingdom ${ }^{1}$ Haiqing $\mathrm{Yu}^{2}$
}

\author{
RMIT UNIVERSITY
}

haiqing.yu [AT] rmit.edu.au

\begin{abstract}
:
This article examines the rise of eSports in China in the context of China's promotion of digital economy and digital platforms. It argues that the rise of the eSports Middle Kingdom is an example of a collaborative effort by the moneypower alliance to use the logic of digital capitalism to realize the Chinese Dream. It focuses on two of Chinese internet and e-commerce heavyweights-Alibaba and Tencent-and examines their aggregated and global expansion strategies through eSports. This is pertinent to the current discussion on Chinese digital platforms' Asia-Pacific expansion. It is also significant in that China has not only taken on South Korea as the mecca of eSports but also taken over North America and Europe as the world's largest eSports market. The article ultimately outlines how politics, capitalism, and nationalism are intertwined in investing in and staging live eSports spectacles in China.
\end{abstract}

Keywords: eSports, Digital Platform, Digital Economy, Money-Power Alliance, Alibaba, Tencent

\section{Introduction}

In recent years, "platform" has become arguably the most prominent term in popular and academic jargons. It ranges from technologies (both hardware and software) to content and culture, from services and products to business patterns and models. Social media networks (from YouTube and Facebook to Weibo and WeChat)-regarded as important digital platforms that facilitate the transnational flows and grassroots-led bottom-up distribution and consumption of popular cultural products such as music and videos ${ }^{3}$-are part of the platform capitalism and platform imperialism discourses. ${ }^{4}$ Similarly, e-commerce platforms 
(from Amazon to Taobao) are part of the platform-based digital economy. As Nick Srnicek points out, platforms-be they advertising, cloud, industrial, product, or lean platformsexist in various combinations and share similar business logics and interrelated tendencies. These are the "expansion of [data] extraction, position as a gatekeeper, convergence of markets, and the enclosure of ecosystems." In other words, we have witnessed the expansion of digital territories and the extension of business ecosystems both online and offline by major players. At the same time, they are also creating enclosed proprietary ecosystems to maintain competitive advantage over others (such as developing closed apps).

China is no exception to platform capitalism. It is known that China and digital capitalism are two pillars of global economy and that "China's digital economy is a global trailblazer." 6 This is a result of the state-centered approach in economic development and restructuring, particularly since the 2008 global financial crisis, with an emphasis on developing cutting-edge digital technologies, platforms, infrastructure, and economy to ensure China's leadership in emerging technologies such as artificial intelligence (AI). As Yu Hong argues, the Chinese state plays a key role in fostering a sophisticated communicative ecosystem-a system that has been spearheaded by entrepreneurial bureaucrats, transnational capitalists and their representatives within and outside China, an outward-looking middle class, and China's own digital champions. ${ }^{7}$ Among the digital champions, BAT (Baidu, Alibaba, and Tencent) and their competitors have been at the forefront to challenge the platform imperialism thesis and transform global platform capitalism.

It is against this backdrop that we have witnessed the rise of eSports in China and the rise of China as the world's largest eSports market. The term "eSports" refers to "the electronic sport and the leagues that compete through networked games and related activities." It is characterized by "high-end competition where people are getting paid for playing computer games ... and an emergent formal structuring of gaming as a sport." ${ }^{9}$ With the boom of internet broadcasting and live streaming platforms in the past decade, eSports has seen the seamless integration of online and offline consumption through game playing, viewing, narrating, training, and management. Although eSports competitions and tournaments are now held in stadiums as media spectacles, consumers of eSports primarily follow competitions through game-streaming platforms such as Twitch and Afreeca (or NeoTV and WeGame), with nonbroadcasted matches generally reported through social media such as Twitter and Facebook (or Weibo, QQ, and WeChat). As such, eSports should be any video game that is played for competitive purposes and produced and broadcasted for viewer consumption over any electronic medium, such as television, smartphone, tablet, or computer.

This article reviews the rise of eSports in China. More importantly, it discusses the role of Chinese digital champions in expanding the influence and raising the stakes of eSports as part of their aggregated and global expansion strategies. This is pertinent to the current discussion on Chinese digital platforms' Asia-Pacific expansion and relevant to the recent announcement by the Olympic Council of Asia (OCA) that eSports will be introduced as a demonstration sport at the 2018 Asian Games in Indonesia and as an official sport at the Hangzhou Games in 2022. It is also significant in that China has not only taken on South Korea as the mecca of eSports but also taken over North America and Europe as the world's largest eSports market. The article ultimately outlines how politics, capitalism, and nationalism are intertwined in investing in and staging live eSports spectacles in China. 


\section{The Rise of the Digital Economy in China}

The rise of eSports in China is also the story of China's rise as the world-leading digital economy. This section reviews the expansion of the digital economy in China. It discusses China's strategic move to establish an advanced digital ecosystem with two key purposes: economic restructuring from manufacture-centered to knowledge economy, and the Chinese dream to lead in key digital technologies and industries.

China is among many Asian countries (particularly Singapore, Indonesia, India, and Korea) that have experienced exponential growth and broad application of digitized information, knowledge, production, and consumption. Digital economy is characterized by the use of modern information networks and communication technologies-such as the internet, cloud computing, big data, the Internet of Things (IoT), and FinTech-to transform social interactions, drive productivity, stimulate innovation, and enable economic activities to be more flexible, agile, and smart. From hardware (e.g., Lenovo, Huawei, Samsung, and Sony) to software (AI, cloud computing, and various digital payment systems), from content (manga, anime, Hallyu dramas and music, and Chinese blockbusters) to platform (WeChat, Taobao, Line, and Paytm), Asian digital economy is not simply on the rise but challenges the "platform imperialism" thesis which argues that Western-based digital platform empires (such as Facebook, YouTube, and Twitter) will continue to dominate the global digital platform markets, despite the increasing competition from emerging companies and countercultural flow from non-Western countries in the twenty-first century. ${ }^{10}$ It is argued that the global digital divide or international hierarchy in the digital economy with US-led platforms at the top will continue to characterize the world order, as the giants continue to expand "their dominance in the name of mergers and acquisitions," leaving a trail of local-based platforms struggling for survival. ${ }^{11}$ However, Asia-based digital companies and unicorns have not only attracted an increasing amount of investment from Western venture capital and private equity fund ${ }^{12}$ but have also gained similar portfolios as their Western counterparts with their deepened entanglement with transnational capitals and markets.

In China, the digital economy has surged since 2015, with a 30.61 percent share of the nation's 2016 gross domestic product (GDP). ${ }^{13}$ It is poised to "set the world's digital frontier" and a leading global force in key digital areas, including virtual reality, three-dimesional printing, drones, robotics, AI, and driveless cars. ${ }^{14}$ The digital economy is seen by Chinese political and business leaders as a critical lever for economic restructuring that steers the country from a low-wage assembly model dependent on foreign technology to an innovation nation with the "created in China" brand. ${ }^{15}$ The Chinese state has led the digital drive and laid out China's digital future through the "Internet Plus" strategy and "mass entrepreneurship and mass innovation" blueprint, which were proposed by Chinese Premier Li Keqiang and written into the government report in 2015. Such an "Internet Plus" strategy is essentially a Chinese rendition of the digital economy or the economy of tomorrow in the "third industrial revolution," with key movers and shakers (such as BAT) working closely with the government to realize the "China rise" dream. ${ }^{16}$

As movers and shakers of Chinese digital economy, BAT and others have been building their digital business empires in a few key proxy warzones, such as e-literature, e-video production and streaming, ${ }^{17}$ e-commerce, and eSports. The role of e-commerce heavyweights in 
the Chinese eSports industry is noteworthy for its scale and intensity. China is not only the largest e-commerce market in the world with the largest e-payment transaction volumes. The rise of e-commerce in China is also the story of a digital "turf war" fought by 8848, EachNet, Dangdang, Alibaba, Jingdong, Suning, and other e-commerce platforms, with Alibaba as the biggest winner (China B2B Research Centre, 2009). From its establishment in 1999 to its record-breaking Initial Public Offering on the New York Stock Exchange in 2014, Alibaba has spearheaded e-commerce development in China and changed Chinese business and consumption patterns and behaviors. Its $\mathrm{C} 2 \mathrm{C}$ (customer to customer) retail platform Taobao.com and its B2C (business to customer) retail platform Tmall.com are the world's two largest e-commerce sites. Alibaba's dominance in e-commerce has always been challenged by equally ambitious digital commerce and social commerce players, especially Tencent (in collaboration with Jingdong). Increasingly, they share similar portfolios in their digital ecosystems. The eSports sector is one battlefield and part of their digital ecosystems, as discussed later in the article.

\section{The Rise of the eSports Central Kingdom}

The internet was available to the public in China in 1996, so was online gaming. Competitive gaming started in 1999, marked by the first unofficial online StarCraft championship. This year also marks the start of social media, with the launch of ChinaRen and QQ to kick off social messaging, social networking, and social gaming in China. ${ }^{18}$ The following timeline, (Table 1) based on $\mathrm{Lu}^{19}$ is illustrative of the key events and players in the rise and development of Chinese eSports industry between 1996 and 2003.

Internet cafés have functioned as incubators of casual gaming and competitive gaming. The release of StarCraft in 1998 coincided with the increased investment in the PC and internet market. Its popularity among Chinese gamers led to the growth of internet cafés (see Figure 1), which provided the technical infrastructure and social setting for networking, community building, nurturing online gaming culture, and forming fan communities among the young people, just like the PC bangs in Korea. ${ }^{20}$ Internet cafés are equipped with the "spawn installation" feature within games, where additional copies could be installed on multiple computers with several limitations. This means that in an internet café where a large network of computers exists, the cost of purchasing software (e.g., StarCraft) is decreased to meet the demand of a large number of players.

The role of internet cafés in Chinese gaming culture is controversial. They have no doubt nurtured a vibrant gaming culture and pioneered the gaming industry through their role in organizing and sponsoring local and regional competitions. Many professional gamers honed their skills and game designers tested their prototypes in internet cafés. ${ }^{22}$ Internet cafés have also been blamed for various social problems, such as youth internet/games addiction and subsequent youth delinquency, behavioral problems, addiction-related violence and crimes, and even death due to overplaying. ${ }^{23}$ These are on top of health and safety issues, particularly concerning the illegal and underground internet cafés that have been closed down since 2011 by the authorities in a national drive to encourage internet café chain operations to exercise stronger self regulation and censorship. ${ }^{24}$ This is shown in the decreasing number of internet cafés in 2012 and 2013 (see Figure 1). 
Table 1. Chinese eSports 1996-2003.

\begin{tabular}{|c|c|}
\hline Year & Major eSports events in China \\
\hline 1996 & $\begin{array}{l}\text { - Westwood Studios' Command E Conquer: Red Alert; RTS (real-time strategy) games introducing } \\
\text { competitive gaming in China } \\
\text { - The internet was open to the public }\end{array}$ \\
\hline 1997 & $\begin{array}{l}\text { - Id Software's Quake II; FPS (first-person shooter) games taking roots in China } \\
\text { - Chinese games coming onto the stage, for example, The Legend of Swordsman }\end{array}$ \\
\hline 1998 & $\begin{array}{l}\text { - Release of Blizzard's StarCraft } \\
\text { - Unofficial domestic servers for the game; teams formed } \\
\text { - Internet cafés grew } \\
\text { - China StarCraft Association (CSA) was formed by gamers } \\
\text { - First official online competitive gaming event (Quake II tournament) was organized by } \\
\text { Shenzhen Telecommunication Bureau }\end{array}$ \\
\hline 1999 & $\begin{array}{l}\text { - First unofficial StarCraft competition (online and offline) organized by Beijing 263, PC } \\
\text { newspapers, computer hardware and software companies, and internet cafés } \\
\text { - QQ was launched and helped the growth of gamer communities }\end{array}$ \\
\hline 2000 & $\begin{array}{l}\text { - First official StarCraft tournament, organized by Aomei Soft (official distributor of StarCraft) } \\
\text { - Chd sponsored by a computer school with RMB 1,000 in the prize money } \\
\text { - E-Sports as a profession: the start of professional gamers } \\
\text { - World Cyber Games (WCG) was formed in South Korea } \\
\text { - Release of Valve's Counter-Strike }\end{array}$ \\
\hline 2001 & - Chinese won two champions in WCG 2001 \\
\hline 2002 & $\begin{array}{l}\text { - First Counter-Strike China E-Sports Tournament by Aomei Soft and Beijing Great Wall } \\
\text { Broadband Network Service }\end{array}$ \\
\hline 2003 & $\begin{array}{l}\text { - Chinese won three gold medals, one silver and one bronze in } 2003 \text { WCG Seoul, broadcast by } \\
\text { CCTV (Chinese Central Television) } \\
\text { - } \text { eSports was officially recognized by the Sports Ministry as a formal sport } \\
\text { - GTV, the first video gaming TV channel, was launched by Liaoning TV } \\
\text { - NetEase released Fantasy Westward Journey, the most popular Chinese multiplayer online } \\
\text { role-playing game (MMORPG) } \\
\text { - Valve's Defense of the Ancients (DotA) was released }\end{array}$ \\
\hline
\end{tabular}

Amid the public concern over internet and games addiction, the Chinese government has taken a double track: It decries the negative impact of online gaming and regulates the online gaming industry in the name of promoting a healthy internet culture, on the one hand, ${ }^{2}$ yet at the same time it encourages the growth of competitive gaming and healthy eSports at the national and international levels. Professional eSports players are regarded as athletes, not addicts. They become national heroes when they win prizes at international eSports competitions.

National governments are significant driving forces in the games industry, such as Korea and Japan. ${ }^{26}$ Similar to Korea where the government has encouraged the growth of the eSports industry to boost the economy as a response to the 1997 Asian Financial Crisis, the Chinese government has shown a positive attitude toward eSports and supported its growth. From 2003 when eSports was recognized as an official sport to 2016 when eSports was 
Number of Internet Cafés (thousand)

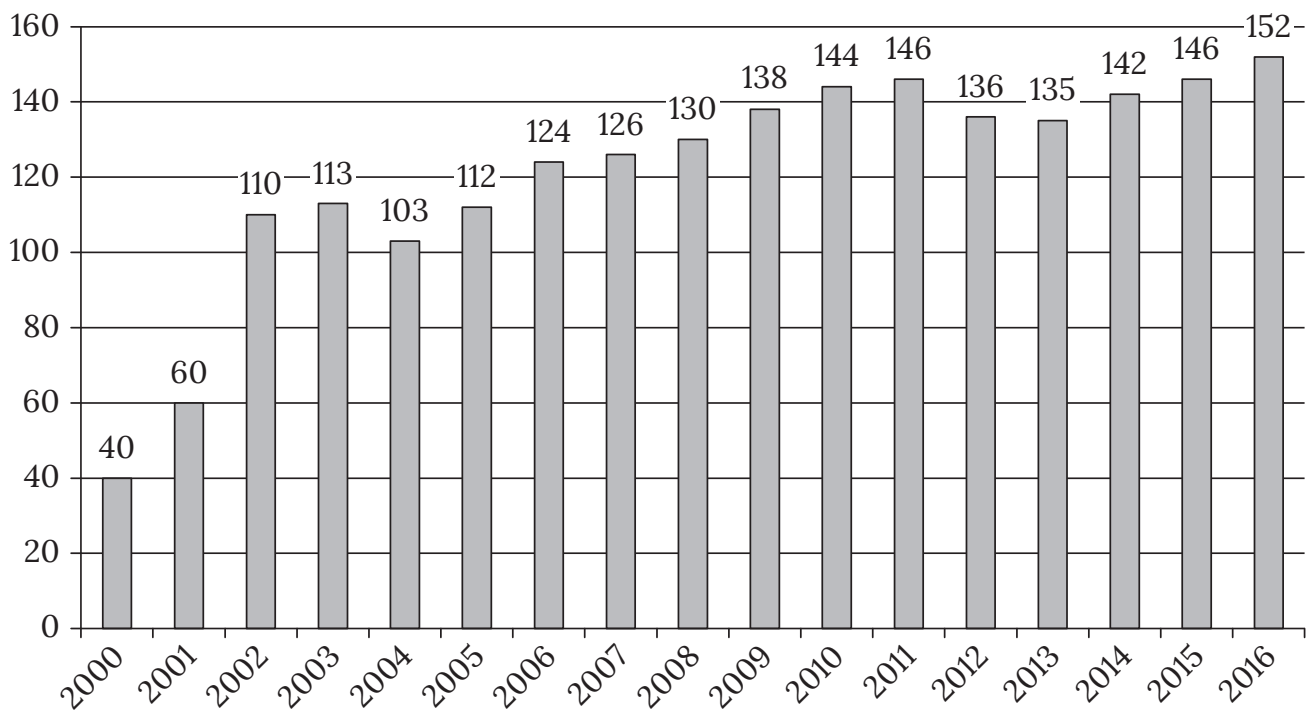

Figure 1. Number of internet cafés in China, 2000-2016. ${ }^{21}$

promoted by the State Council as part of fitness and leisure industries and by Ministry of Education as an undergraduate major, the Chinese government has aggressively sought to legitimate eSports as a source of national pride and international goodwill.

As discussed earlier, the Chinese government is the major proponent of the digital economy and eSports. A techno-nationalist discourse has underlined the state policy toward China's digital economy, that is, to nurture the domestic market, to support joint ventures with foreign companies and venture capital, and to promote Chinese companies' international competitiveness. Chinese eSports players winning prizes and gold medals at international competitions like the World Cyber Games (WCG) prompted the state governing body of sports to recognize eSports as an official sport in 2003. Now young people are called upon to devote their bodies and minds to the Chinese Dream. Training in eSports skills is as patriotic as "training the body for China." ${ }^{27}$ Live eSports competitions are presented as media spectacles that nurture the ideal patriotic citizen, just like any other major events-for instance, the Olympics or the national games; accordingly, eSports has become a platform to display carefully crafted nationalism and China's soft power. ${ }^{28}$

Hence, we have witnessed seemingly contradictory policies toward eSports and online gaming: regulations aiming at minimizing negative social impact and gaming addition ${ }^{29}$ while $^{2}$ encouraging a pragmatic nationalism that sees Chinese eSports players winning in international competitions. As Hjorth and Chan have noted, both Korea and Japan have successfully casted themselves as the center of Asian games market and leaders of "techno-cool." ${ }^{30}$ Even Taiwan has caught up with the techno bandwagon. China is no longer content to be a follower; it aspires to be a leader in the digital playfield. It already takes the lead in the Olympics gold medal tally. To lead in the eSports gold medal tally is its next goal.

The key strategy is working with leaders in the industry to lead in the future. Like coproductions in the film industry, ${ }^{31}$ the Chinese gaming industry has collaborated with major stakeholders in 
the international eSports industry, such as Korea. Since the early 2000s, China has worked with Korea to expand the eSports market, such as the former's heavy involvement in the WCG, an effort that has now resulted in eSports being included in the official program of the 2022 Asian Games in Hangzhou. Although the power balance between these two countries was initially tipped in favor of Korea, the Chinese market has inflated in the past decade and its influence continues to grow (Jin, 2010). Using their immense wealth and resources, Chinese companies have successfully acquired major Korean gaming companies (such as Longzhu Gaming), as well as recruiting prominent South Korean players such as Cho "Mata" Se-hyeong. ${ }^{32}$ This has allowed China to strengthen its place in the eSports industry. ${ }^{33}$

China became the world's largest online gaming market in 2009 and overtook the United States as the world's largest eSports market in 2016. It is also the largest video gaming and mobile gaming market in the world. It generates more than one-quarter of game revenues worldwide, with Tencent and NetEase taking the lead and mobile gaming dominating the market (63 percent) and continuing to drive growth. ${ }^{34}$

Such a huge market has not only seen private companies and internet giants investing in the eSports industry (as discussed in the next section); numerous jobs and employment opportunities have opened for young underemployed university graduates. The recognition of eSports as a university major in 2006 is a push from the top for millions of young people to devote their lives to eSports. Like elsewhere in the world, eSports has attracted young people as professional players and commentators, who are able to earn more money than "regular" employment in 9-to-5 jobs. ${ }^{35}$ Some Chinese professional gaming teams have earned cult-like status among millions of domestic gamers and are leading contenders at most worldwide eSports tournaments.

From a humble start in 1999 to the world's largest eSports market in 2016, the Chinese eSports market has continued to grow exponentially, with multiplayer online battle arena (MOBA, also known as action real-time strategy or ARTS) the most popular genre of games (e.g., League of Legend, Dota 2, and Honour of Kings [HoK]) and hence extremely attractive to advertisers and businesses. ${ }^{36}$ An eSports value chain has formed, with key e-commerce and social gaming champions taking a leading role (see Table 2). In 2017 the Chinese eSports market size has reached US\$1.26 billion (excluding the revenue from gamers playing eSports games), with more than two hundred million fans, the most top-ranked competitors and teams, and the most advanced eSports infrastructure and venues. ${ }^{37}$

Table 2. Chinese eSports Value Chain

\begin{tabular}{|c|c|}
\hline Participants & Examples \\
\hline $\begin{array}{l}\text { Developer/Publishers and distributors } \\
\text { (companies that make the games or } \\
\text { distribute the games) }\end{array}$ & $\begin{array}{l}\text { Tencent-Riot Games (League of Legends; Honour of Kings); Blizzard } \\
\text { Entertainment (World of Warcraft, Hearthstone, StarCraft); Valve } \\
\text { (Dota 2, Counter-Strike, Half-Life); NEXON } \\
\text { NetEase, Shanda, Kingsoft, Perfect World, Tian City }\end{array}$ \\
\hline $\begin{array}{l}\text { Leagues (organizers of tournaments) } \\
\text { and competitions }\end{array}$ & $\begin{array}{l}\text { Alibaba's WESG tournaments; Tencent's LoL, CF, KPL, LPL } \\
\text { tournaments, and QGC (a mobile gaming competition); Valve's } \\
\text { Dota 2-TI; Geeya's WCA, Zhejiang Daily Digital's NEST (National } \\
\text { Electronic Sports Tournaments), WECG; WCA, WESM, Wang } \\
\text { Sicong's Hero Pro League; Shanda's WEGL' }\end{array}$ \\
\hline
\end{tabular}




\begin{tabular}{|c|c|}
\hline Participants & Examples \\
\hline $\begin{array}{l}\text { Teams and clubs, and their associations } \\
\text { or alliances }\end{array}$ & $\begin{array}{l}\text { KPL Alliance, China Mobile eSports Alliance }{ }^{39} \text { Hero Alliance } \\
\text { NewBee, Invictus Gaming (Wang Sicong), Suning Gaming, JD } \\
\text { Gaming }\end{array}$ \\
\hline $\begin{array}{l}\text { Platforms (broadcasting channels and } \\
\text { streaming platforms) }\end{array}$ & $\begin{array}{l}\text { Live streaming video platforms: e.g., Twitch, Steam, Tencent's } \\
\text { WeGame and QQJoy (QQ mobile games), battlenet, Douyu, Zhangqi, } \\
\text { huya, Longzhu), NeoTV } \\
\text { TV channels: Game FY and GTV }\end{array}$ \\
\hline $\begin{array}{l}\text { Player agents/managers and event } \\
\text { organizers }\end{array}$ & $\begin{array}{l}\text { Hero Entertainment; China Mobile Games and Entertainment; } \\
\text { Chengdu, Wuhu, Changzhou (agents of pro-gamers; cities and } \\
\text { companies that provide infrastructure and event management for } \\
\text { tournaments) }\end{array}$ \\
\hline Brands/Sponsors & $\begin{array}{l}\text { Alibaba, Intel, Tencent, Samsung, Logitech, and various streamers } \\
\text { and broadcasters (companies that sponsor teams, leagues, } \\
\text { publishers, etc.) }\end{array}$ \\
\hline Pro-gamers/Commentators & Sky, EHOME, Iceice, y', bLink, Shadow \\
\hline
\end{tabular}

WCA = World Cyber Arena; WECG = World Esports Championship Games; WESG = World Electronic Sports Games; WEGL $=$ World Esports Games \& Leagues; KPL = Kings Pro League; LoL = League of Legends; LPL = League of Legends Pro League; $\mathrm{CF}=$ CrossFire.

\section{Digital Champions Weighing In}

The rapid growth of the eSports industry has attracted some of China's largest e-commerce and social commerce companies to the market, with the likes of Tencent, Alibaba, Jingdong, and Suning acquiring key assets across the value chain. As discussed earlier, competition, expansion, and synergy have characterized the strategies of key digital players to consolidate their platform dominance and expand their digital ecosystems. The eSports sector is one such battlefield. As Chinese eSports competitions moved from the internet cafés to sports stadiums and video streaming platforms, their sponsors have also shifted from internet cafés and computer companies to IT companies, media companies, and e-commerce and social commerce platforms. Chinese digital companies have also moved up the value chain from distributors (of foreign intellectual property [IP]) to game publishers and league owners.

China's biggest social media, social gaming, and social commerce player, Tencent, owns the biggest eSports franchise. It has made all the right moves to expand mobile gaming and eSports, most recently in moving up the gaming industry value chain by buying and controlling market and assets. It saw the potential for the MOBA game from its inception in the early 2000s when eSports in Korea took off. It has since made carefully paced moves to not only lead in the Chinese gaming market but also in the global eSports industry, through part or complete ownership of the world's leading games publishers and developers of popular games.

Tencent first became a Chinese distributor for Riot Games' League of Legends (LoL) in November 2008. The next year it made an initial investment in Riot Games (United States), and in 2015, it 100 percent owned the company. It has become the developer, publisher, and distributor of popular games, as well as the owner and operator of popular eSports leagues around LoL and HoK. The 2017 LoL World Championship, held for the first time in China, is recognition of China's coming of age in the eSports market. ${ }^{41}$ 
Tencent aims to embrace all game genres and has acquired at least 10 percent share in Activision Blizzard (United States), whose eSports branch Blizzard Entertainment owns and operates popular eSports leagues around World of Warcraft, StarCraft 2, Hearthstone, and Heroes of the Storm. It is said that indirectly "Tencent partially controls about a third of the revenues generated by the top 10 global companies, according to game revenues. ${ }^{22}$ Tencent is growing its share of Western games market and in 2016 bought Finland's Supercell (which created the hit mobile game Clash of Clans).

Tencent is not only growing its IP and content assets in the upper stream of the value chain but also the distribution channels in the middle stream. Its WeGame platform is now taking on Valve's Steam to become the biggest international community on the world's largest gaming platform. ${ }^{43}$ The Penguin (Tencent's logo) games empire is all-dimensional in its expansionist strategies. Apart from running its own eSports teams like the KPL (Honour of Kings Pro League) Alliance, it has played a mediator's role in helping its e-commerce partner JD.com (Tencent holds 20 percent shares of JD) and e-commerce competitor Suning (Alibaba holds 19.99 percent shares of Suning) to form JD Gaming and Suning Gaming in 2016. JD Gaming and Suning Gaming have gone through acquisitions and restructuring of eSports clubs and teams (including Korean LoL team Longzhu Gaming by Suning) to compete in LPL (League of Legends Pro League) tournaments. ${ }^{44}$

Tencent's partner JD is probably the most serious competitor of Alibaba and second largest e-commerce player in China. The two e-commerce heavyweights vie for championship in revenues on June 18 (known as 618, the big discount festival or the mid-year shopping festival) and November 11 (known as Double 11, the largest online shopping festival in China). JD.com was founded on June 18, 2004. The 618 online shopping festival was meant to celebrate its anniversary, but it has been joined by all major e-commerce players, including Alibaba's Tmall, Suning, and Dangdang, in the enclosure battle and price war with JD.com. Double 11 is the day to celebrate the creation of Alibaba's Tmall. It too has become a battle among e-commerce heavyweights to fight for revenue and market share.

Alibaba's involvement in eSports was as early as 2006, when the World eSports Masters (WEM) (founded in 2004 in Seoul) moved its base to Hangzhou, sponsored by AliSports in partnerships with Aegis Gaming Networks Inc. (Korean) and Global Mobile Game Confederation (China). In 2016, AliSports pledged to invest US\$150 million in International E-Sports Federation over the next three years. It established Changzhou (Jiangsu Province) as China's eSports capital, where the World Electronic Sports Games (WESG) tournament was held in December 2017. WESG is Alibaba's effort to replace the WCG series of South Korea (2000-2013) as the Olympics of eSports, ${ }^{45}$ with the launch of 1,200 events across fifteen cities in China in 2017. The e-commerce giant offered a whopping US\$5.5 million prize pool, for teams competing in Counter-Strike: Global Offensive, Dota 2, Hearthstone, and StarCraft $2 .{ }^{46}$ So far, AliSports' WESG is the world's highest paying eSports tournament. It directly challenges Tencent's LoL tournaments and leagues. The competition between the two digital giants gets intense.

The year 2016 marks the beginning of official "marriage" of China's e-commerce heavyweights with the eSports industry. Led by Tencent and Alibaba and joined by their strategic partners in e-commerce JD.com and Suning, respectively (as well as a string of other digital players like Baidu and NetEase), Chinese eSports industry has grown bigger in 
scale, which is evidenced in the competition between Tencent and Alibaba to establish their own proprietary eSports empires.

Alibaba has worked with local governments to make Hangzhou and Changzhou China's eSports capitals. Tencent is turning Wuhu (Anhui province) into an eSports town, featuring an eSports theme park, an eSports university, a cultural and creative park, and an animation industrial park. ${ }^{47}$ The social and mobile gaming giant is also building an eSports theme park in Chengdu (Sichuan Province), featuring its popular mobile fantasy role-playing game HoK (with two hundred million users in 2017). ${ }^{48}$ The aim is to bring social gaming and competitive gaming into a new digital gaming platform "WeGame" TGA (Tencent Games Arena). As Table 2 illustrates, Tencent has moved up the gaming industry value chain from being the king of mobile gaming to being the publisher and league owner and operator of LPL, LSPL (LoL Secondary Pro League), and a range of other popular games such as CF (CrossFire). Tencent has further consolidated its leading role in Chinese gaming industry. The challenge from Alibaba and others is getting more intense. China is now the powerhouse with big money and big data to reshape the global eSports landscape.

As discussed earlier in this article, Chinese digital players-from hardware to software companies, from content providers to platform and proprietary owners-have been incorporated into the state-centered "Chinese Dream" narrative. They have competed with one another in the digital economy drive and worked with one another to challenge the "platform imperialism" thesis. Centered around the party-state and in response to its "Internet Plus" strategy, the Chinese digital money-power alliance has aimed to make eSports a national obsession and China the new mecca of eSports. Tencent, Alibaba, their e-commerce partners and collaborators, and a wide array of Chinese digital technology and communication players have taken on the mission to reshape the future of eSports, not only by raising the stakes but also by making it more mobile and agile.

\section{Conclusion}

The rise of eSports in China is a corporate strategy to spread their digital footprint, as well as a national move to stimulate growth in the digital economy. Chinese digital empires such as Tencent and Alibaba and digital heavyweights such as Lenovo, Huawei, JD, and Suning are not only controlling their own national markets but also competing with Western platform empires in key strategic areas. The investment in the games industry and prioritization of eSports as a strategic area-regarded as the golden goose ${ }^{49}$-are concerted moves to stimulate national economy and encourage innovative business practices to achieve leadership in creative and digital economy.

The rise of eSports in China is a story of the digital enclosure movement involving Chinese digital empires and heavyweights. It is also a story of public-private alliance (state-business collaboration) in promoting, regulating, and incorporating private resources and players into the orbit of the Chinese dream. The Chinese grand strategy is to take advantage of "Internet Plus" and digital economy to successfully transition away from manufacturing and agriculture to the services sector, to increase the digital and innovative intensity of the Chinese economy. Digital platforms take advantage of the favorable environment created by the 
protective policies (such as China's internet control and censorship against major Western digital platforms such as Google); they also work with the government to realize its own political goals, such as improving China's status in international competitive events, be they the Olympics Games or the Olympics of eSports. Nationalism by itself is not enough to encourage young people to engage in a precarious industry with a very short life span and unguaranteed future. Big money investment in the industry and a big prize money pool have attracted more than two hundred million active players and many more jobs and employment opportunities in the eSports value chain, from running internet cafés to eSports live steaming and commentating businesses, to team and events management, publicity, and public relations (PR) promotion (see Table 2). It is a young industry adopted by an old nation, which aspires to be rejuvenated in the twenty-first century. China is now the most active eSports market in the world, with more events and tournaments than any other country. As this article has illustrated, the digital empires Alibaba and Tencent are sponsoring and buying the world's leading eSports tournaments, companies, and leagues, whereas second-tier players like Suning and Shanda are acquiring Korean companies and teams. From learning from the West to working with and buying eSports assets of the West and Korea, China's money-power alliance is on track to make eSports a national obsession and China the new mecca of eSports.

The rise of China as an epicenter in the global eSports industry is therefore more about China's role in an interconnected world of digital economy. It can have global repercussions. It is not simply about gaming and entertainment: there are potentially serious geopolitical and legal implications and debates about ethics, race, ethnicity, and nationality. This is represented in the phenomenon of "gold farmers," young men who are employed by gaming sweatshops (third-party gaming services industry) to play online games to generate virtual coinage that can be sold and transferred as real-world currencies. ${ }^{50}$ The view from the West is typical of a third-world stereotype of China, comparable with the nineteenth-century discourse about Chinese immigrants in the United States. ${ }^{51}$ A closer look at the profile of Chinese gold farmers will find that they are educated and well-off (colleague graduates and university students from middle-class families). They play online games (typically WoW) full-time or part-time to get paid for selling virtual goods to Chinese and Korean markets more than the Western ones. ${ }^{52}$

The Chinese are not amused by the Western stereotype of third-world Chinese gold farmers who drudge away for first-world customers. As a mid-income country and the second largest economy in the world, China wants to be respected as a responsible player and trendsetter in the global eSports industry. It has made a concerted effort to increase China's overall national capacity as a leader, not follower in the new digital economy (which China sees as an opportunity to leap-frog and surpass the United States and the West). The rise of the eSports Middle Kingdom is an example of a collaborative effort by the money-power alliance to use the logic of digital capitalism to realize the Chinese dream. The game is on.

${ }^{1}$ Research for this article was funded through the Australian Research Council Discovery Project (DP170102176), titled Digital China: From Cultural Presence to Innovative Nation.

${ }^{2}$ Haiqing Yu is Associate Professor and Vice-Chancellor's Principal Research Fellow in the School of Media and Communication, RMIT University. Her research focuses on China's digital media, communication, and culture and their sociopolitical and economic impact in China, Australia, and the Asia-Pacific. 
${ }^{3}$ Chua Beng Huat and Jung Sun, "Social Media and Cross-border Cultural Transmissions in Asia: State, Industries, Audiences," International Journal of Cultural Studies 17 (5, 2014): 417-22.

${ }^{4}$ See Nick Srnicek, Platform Capitalism (London: Polity Press, 2017).

${ }^{5}$ Srnicek, Platform Capitalism, 98.

${ }^{6}$ John Thornhill, "China's Digital Economy Is a Global Trailblazer," Financial Times, March 21, 2017, https://www.ft.com/content/86cbda82-0d55-11e7-b030-76895 4394623?mhq5j=e7.

${ }^{7}$ Yu Hong, Networking China: The Digital Transformation of the Chinese Economy (Urbana: University of Illinois Press, 2017).

${ }^{8}$ Dal Yong Jin, Korea's Online Gaming Empire (Cambridge: MIT Press, 2010), 59.

${ }^{9}$ T. L. Taylor, Raising the Stakes: E-Sports and the Professionalization of Computer Gaming (Cambridge: MIT Press, 2012), 9.

${ }^{10}$ Dal Yong Jin, Digital Platforms, Imperialism and Political Culture (London: Routledge, 2015).

${ }^{11}$ Dal Yong Jin, "Digital Platform as a Double-edged Sword: How to Interpret Cultural Flows in the Platform Era," International Journal of Communication 11 (2017): 3880-98, 3894.

12 "Unicorns" refer to startups without an established performance record but with estimated valuation of more than US\$1 billion.

${ }^{13}$ China Daily, "Top 10 Provincial Regions in Digital Economy," May 8, 2017, http:// www.chinadaily.com.cn/bizchina/2017top10/2017-05/08/content_29241255 .htm.

${ }^{14}$ Jonathan Woetzel, et al., "China's Digital Economy: A Leading Global Force," McKinsey Report, 2017, https://www.mckinsey.com/global-themes/china/chinasdigital-economy-a-leading-global-force.

${ }^{15}$ Yu Hong, "Pivot to Internet Plus: Molding China's Digital Economy for Economic Restructuring?" International Journal of Communication 11 (2017): 1486-506; Michael Keane, Created in China: The Great New Leap Forward (NY: Routledge, 2007).

${ }^{16}$ For the "third industrial revolution," see: Jeremy Rifkin, The Third Industrial Revolution (NY: Palgrave Macmillan, 2011); Elena Holodny, "Jeremy Rifkin Interview," Business Insider, July 17, 2017, https://www.businessinsider.com.au/jeremyrifkin-interview-2017-6?r=US\&IR=T. For the concept of "China's rise" see: Zheng Bijian, China's Road to Peaceful Rise, trans. Sun Miaoyi and Shi Yanhua (Abingdon: Routledge, 2011).

17 Technode, "Chinese Video Giants Are Becoming Production Powerhouses," October 13, 2017, http://technode.com/2017/10/13/chinese-video-giant-productionpowerhouses /.

${ }_{18}$ Mark McLelland, Haiqing Yu and Gerard Goggin, "Alternative Histories of Social Media in Japan and China," in Sage Handbook on Social Media, eds. Jean Burgess, Alice Marwick, and Thomas Poell (Thousand Oaks, CA: SAGE, 2017), 53-68.

${ }^{19}$ Zhouxiang Lu, "From E-Heroin to E-Sports: The Development of Competitive Gaming in China," The International Journal of the History of Sport 33 (18, 2017): 2186-206.

${ }^{20}$ Dal Yong Jin and Florence Chee, "Age of New Media Empires: A Critical Interpretation of the Korean Online Game Industry," Games and Culture, 3 (1, 2008): 38-58; Jun-sok 
Huhh, "Culture and Business of PC Bangs in Korea," Games and Culture 3 (1, 2008): 26-37; Jun-sok Huhh, "The "Bang" Where Korean Online Gaming Began: The Culture and Business of the PC bang in Korea," in Gaming Cultures and Place in Asia-Pacific, eds. Larissa Hjorth and Dean Chan (London: Routledge 2009), 102-17.

${ }^{21}$ Ministry of Culture of PRC, "2012 nian Zhonggo wangba shichang niandu baogao zhaoyao" [Extract of 2012 Annual Report on Chinese Internet Cafes Market], April 27, 2013, http://www.mcprc.gov.cn/whzx/bnsjdt/whscs/201304/t20130427_346183. html; iResearch, "2007 nian zhongguo wangba shuliang jiang dadao 11.5 wan jia" [Chinese Internet Cafes Will Reach 115K in 2007], June 21, 2005, http://tech.sina .com.cn/i/2005-06-21/1546641983.shtml; Wangyi, "2016 nian wangba shuliang ji shichang hangqing fenxi" [Market Analysis of the Internet Cafes and Market in 2016], 2017, http://www.dnzmkg.com/news/hydt/2017-06-08/289.html.

${ }^{22}$ The role of the young fan communities in Chinese gaming and eSports industries is worth elaboration. It is not within the scope of this article (focusing on the industry and digital platforms), however, to give due analysis to this important topic.

${ }^{23}$ Qiaolei Jiang and Louis Leung, "Internet Addiction," in The Internet in China: An Encyclopaedic Handbook of Online Business, Information Distribution, and Social Connectivity, eds. Ashley Esarey, et al. (Great Barrington, Mass.: Berkshire Publishing, 2015), 30-237; Lu, "From E-Heroin to E-Sports."

${ }^{24} \mathrm{Lu}$ Wei and Wen Chen, "Internet Cafés," in The Internet in China: An Encyclopaedic Handbook of Online Business, Information Distribution, and Social Connectivity, eds. Ashley Esarey, et al. (Great Barrington, Mass.: Berkshire Publishing, 2015), 204-10.

${ }^{25}$ Jiang and Leung, "Internet Addiction"; Mirko Ernkvist and Patrik Ström, "Enmeshed in Games with the Government: Governmental Policies and the Development of the Chinese Online Game Industry," Games and Culture 3 (1, 2008): 98-126.

${ }^{26}$ Dal Yong Jin, "The Digital Korean Wave: Local Online Gaming Goes Global," Media International Australia 141 (2011): 128-36; Yuko Aoyama and Hiro Izushi, "Hardware Gimmick or Cultural Innovation? Technological, Cultural and Social Foundations of the Japanese Video Game Industry," Research Policy, 32 (3, 2003): 423-44.

${ }^{27}$ Susan Brownell, Training the Body for China: Sports in the Moral Order of the People's Republic (Chicago: University of Chicago Press, 1995).

${ }^{28}$ Marcella Szablewicz, "A Realm of Mere Representation? 'Live' E-Sports Spectacles and the Crafting of China's Digital Gaming Image," Games and Culture 11 (3, 2016): 256-74.

${ }^{29}$ Alex Golub and Kate Lingley, “Just Like the Qing Empire': Internet Addiction, MMOGs, and Moral Crisis in Contemporary China," Games and Culture 3 (1, 2008): $59-75$.

${ }^{30}$ Larissa Hjorth and Dean Chan, eds., Gaming Cultures and Place in Asia-Pacific (London: Routledge, 2009).

${ }^{31}$ Wendy Su, "A Brave New World?-Understanding U.S.-China Coproductions: Collaboration, Conflicts and Obstacles," Critical Studies in Media Communication 34 (2017): 480-94, doi:10.1080/15295036.2017.1349326.

32 Thiemo Braütigam, "Chinese Retail Group Suning Commerce Acquires Korean Team Longzhu Gaming," The Esports Observer, 2016, https://esportsobserver.com/ chinese-retail-group-suning-commerce-acquires-korean-team-longzhu-gaming/. 
${ }^{33}$ However, it is interesting that while China makes lucrative offers to lure players to join Chinese teams, it is unable to retain players like Cho who chose to eventually return back to Korea. Furthermore, political tensions such as those regarding THAAD (Terminal High Altitude Air Defense) have had implications on the online gaming industry. The Chinese government's boycott of Korean products, tourism, and even its games pose a threat to their history of collaborative engagement. See Tyler Erzberger, "Where Should Mastro Cho 'Mata' Se-hyeong Make His New Home?," ESPN, November 22, 2016, http://www.espn.com.au/esports / story/_/id/18108164/league-legends-where-maestro-cho-mata-se-hyeongcall-new-home; Acho Huang and Josh Horwitz, "Online Video Games Are the Latest Casualty of China's War against Korean Businesses," Quartz Media, March 8, 2017, https://qz.com/928459/online-video-games-are-the-latest-casualtyof-chinas-retaliation-against-korean-businesses-for-the-thaad-antimissiledefense-system/.

${ }^{34}$ Anna McDonald, "The Global Games Market Will Reach \$108.9 Billion in 2017 with Mobile Taking 42\%," Newzoo, April 20, 2017, https://newzoo.com/insights / articles /the-global-games-market-will-reach-108-9-billion-in-2017-with-mobiletaking- $42 /$.

${ }^{35}$ Lisa Hanson, "China (and Asia) Are Driving a Booming Global ESports Market," Forbes, May 9, 2016, https://www.forbes.com/sites/lisachanson/2016/05/09/welcometo-the-world-of-esports-big-globally-but-huge-in-china/\#4f0d85d9703b.

${ }^{36}$ iResearch, "2016 China's E-Sports Content Ecosystem Report," April 28, 2016, http://www.iresearchchina.com/content/details8_21894.html.

${ }^{37} \mathrm{Lu}$, "From E-Heroin to E-Sports."; Woetzel et al., "China's Digital Economy."

${ }^{38}$ WEGL (World Esports Games \& Leagues) is China's leading games company Shanda's move to ride on the back of Korean eSports industry to expand it. It is led by Eyedentity Entertainment, a Korean eSports company acquired by Shanda in 2010. See Sung-won Yoon, "Eyedentity Seeks to Boost Global e-sports Business," The Korea Times, July 19, 2017, http://www.koreatimes.co.kr/www/news/tech / 2017/07/134_233300.html.

${ }^{39}$ China Mobile eSports Alliance (formed in 2015) is composed of key players, such as Baidu, NetEase, and Qihoo 360, as well as various major eSports clubs and their association (Association of China E-sports), game companies (e.g., Perfect World, Giant), eSports teams, event-organizing platforms (Panda TV, Banana Project, Imba TV, Net Fish), UC Browser, and Mobile Hardcore Alliance (formed in 2014, including Huawei, OPPO, Vivo, Lenovo, Coolpad, and Xiaomi).

${ }^{40}$ Many of the broadcasting and streaming platforms are owned by state media or private companies with a strong government background, such as Zhangqi (owned by Zhejiang Daily Digital Culture Group), Game FY (of Shanghai BestTV), GTV (of Chengdu Geeya Technology), and Longzhu (owned by Suning).

${ }^{41}$ It is a paradox that China becomes the world's largest eSports market when the state media has slammed Tencent's popular mobile game Honour of Kings (HoK) for poisoning young people. See China Daily, "China Daily Comments on Honour of Kings: Don't Make Online Gaming Your Whole Life" [Renmin ribao ping wangzhe rongyao: bie rang wangrou chengwei shenghuo de quanbu], 2017, http://www .wlcbnews.com/information/wlcbnews90/msg21592452733.html. 
${ }^{42}$ John Gaudiosi, "This Chinese Tech Giant Owns More Than Riot Games," Fortune, December 22, 2015, http://fortune.com/2015/12/22/tencent-completes-riotgames-acquisition/.

${ }^{43}$ https://venturebeat.com/2017/05/18/how-tencents-wegame-is-changing-tocompete-with-steam-in-china/.

${ }^{44}$ Braütigam, "Chinese Retail Group Suning Commerce Acquires Korean Team Longzhu Gaming."

${ }^{45}$ China has made several efforts to revive and replace World Cyber Games (WCG) as the world's epicenter of eSports, first in 2014 with the start of the World Cyber Arena (WCA) by the Yinchuan municipal government (Northwestern China) in collaboration with Yinchuan International Games Investment Co Ltd. WCA has been held annually in Yinchuan, making it the eSports capital of Western China.

${ }^{46}$ Thiemo Braütigam, "Alibaba Makes 3-year Commitment to one of eSports' Highestpaying Tourneys," January 13, 2017, https://dotesports.com/business/alibabaalisports-3-year-deal-wesg-esports-host-city-changzhou-china-2-4309.

${ }^{47}$ Andrew Tarantola, "Chinese Internet Giant Tencent Is Building an eSports Park," May 16, 2017, https://www.engadget.com/2017/05/16/chinese-internet-gianttencent-is-building-an-esports-park/.

${ }^{48}$ Junjie Wang, "With 50 Million Daily Active Users and 200 Million Registered Users, Why Is the Honor of Kings So Popular?" [5000 wan ri huoyue yonghu, 2 yi xiazai liang, wangzhe rongyao weishenmo hui zhemo huo], IT Times, March 6, 2017, http://www.itxinwen.com/news/news_13893.shtml.

${ }^{49}$ Chun Liu, "Raising the Golden Goose: A Retrospective Analysis of the State's Role in China's Online Game Industry," Media International Australia 149 (2013): 41-54.

${ }^{50}$ Julian Dibbell, "The Life of a Chinese Gold Farmer," New York Times, June 17, 2007, http://www.nytimes.com/2007/06/17/magazine/17lootfarmers-t.html.

${ }^{51}$ Nick Yee, "Yi-Shan-Guan," 2006, http://www.nickyee.com/daedalus/archives / 001493.php.

${ }^{52}$ Bjarke Liboriussen, "Amateur Gold Farming in China: 'Chinese Ingenuity', Independence, and Critique," Games and Culture 11 (3, 2016): 316-31.

\section{Bibliography}

Aoyama, Yuko, and Hiro Izushi. "Hardware Gimmick or Cultural Innovation? Technological, Cultural and Social Foundations of the Japanese Video Game Industry." Research Policy, 32, no. 3 (2003): 423-44.

Braütigam, Thiemo. "Alibaba Makes 3-year Commitment to One of eSports' Highest-paying Tourneys." January 13, 2017. https://dotesports.com/business/alibaba-alisports3-year-deal-wesg-esports-host-city-changzhou-china-2-4309.

Braütigam, Thiemo. "Chinese Retail Group Suning Commerce Acquires Korean Team Longzhu Gaming." The Esports Observer, 2016. https://esportsobserver.com/chinese-retailgroup-suning-commerce-acquires-korean-team-longzhu-gaming/. 
Brownell, Susan. Training the Body for China: Sports in the Moral Order of the People's Republic. Chicago: University of Chicago Press, 1995.

China B2B Research Centre. "1997-2009: Report on China's 12 Years of e-commerce" [19972009: zhongguo dianzi shangwu shi'er nian diaocha baogao]. 2009. http://tech .qq.com/2009921e/ebaogao.doc.

China Daily. "China Daily Comments on Honour of Kings: Don't Make Online Gaming Your Whole Life" [Renmin ribao ping wangzhe rongyao: bie rang wangrou chengwei shenghuo de quanbu]. 2017. http://www.wlcbnews.com/information/wlcbnews90/ msg21592452733.html.

China Daily. "Top 10 Provincial Regions in Digital Economy." May 8, 2017. http://www .chinadaily.com.cn/bizchina/2017top10/2017-05/08/content_29241255.htm.

Chua, Beng Huat, and Jung Sun. "Social Media and Cross-Border Cultural Transmissions in Asia: State, Industries, Audiences." International Journal of Cultural Studies, 17, no. 5 (2014): 417-22.

Dibbell, Julian. "The Life of a Chinese Gold Farmer." New York Times, June 17, 2007. http:// www.nytimes.com/2007/06/17/magazine/17lootfarmers-t.html.

Ernkvist, Mirko, and Patrik Ström. "Enmeshed in Games with the Government: Governmental Policies and the Development of the Chinese Online Game Industry." Games and Culture, 3, no. 1 (2008): 98-126.

Erzberger, Tyler. "Where Should Mastro Cho 'Mata' Se-hyeong Make His New Home?" ESPN, November 22, 2016. http://www.espn.com.au/esports/story/_/id/18108164/ league-legends-where-maestro-cho-mata-se-hyeong-call-new-home.

Gaudiosi, John. "This Chinese Tech Giant Owns More Than Riot Games." Fortune, December 22, 2015. http://fortune.com/2015/12/22/tencent-completes-riotgames-acquisition/.

Golub, Alex, and Kate Lingley. "'Just Like the Qing Empire': Internet Addiction, MMOGs, and Moral Crisis in Contemporary China." Games and Culture, 3, no. 1 (2008): 59-75.

Hanson, Lisa. "China (and Asia) Are Driving a Booming Global eSports Market." Forbes, May 9, 2016. https://www.forbes.com/sites/lisachanson/2016/05/09/welcome-to-theworld-of-esports-big-globally-but-huge-in-china/\#4fod85d9703b.

Hjorth, Larissa, and Dean Chan, eds. Gaming Cultures and Place in Asia-Pacific. London: Routledge, 2009.

Hong, Yu. Networking China: The Digital Transformation of the Chinese Economy. Urbana: University of Illinois Press, 2017.

Hong, Yu. "Pivot to Internet Plus: Molding China's Digital Economy for Economic Restructuring?" International Journal of Communication 11 (2017): 1486-506.

Holodny, Elena. "Jeremy Rifkin Interview." Business Insider, July 17, 2017. https://www .businessinsider.com.au/jeremy-rifkin-interview-2017-6?r=US\&IR=T. 
Huang, Echo, and Josh Horwitz. "Online Video Games Are the Latest Casualty of China's War against Korean Businesses." Quartz Media, March 8, 2017. https://qz.com/928459/ online-video-games-are-the-latest-casualty-of-chinas-retaliation-against-koreanbusinesses-for-the-thaad-antimissile-defense-system/.

Huhh, Jun-sok. "Culture and Business of PC Bangs in Korea." Games and Culture, 3, no. 1 (2008): 26-37.

Huhh, Jun-sok. "The "Bang" Where Korean Online Gaming Began: The Culture and Business of the PC bang in Korea." In Gaming Cultures and Place in Asia-Pacific, edited by Larissa Hjorth and Dean Chan, 102-17. London: Routledge, 2009.

iResearch. "2016 China's E-Sports Content Ecosystem Report." April 28, 2016. http://www .iresearchchina.com/content/details8_21894.html.

iResearch. "2007nian zhongguo wangba shuliang jiang dadao 11.5 wan jia" [Chinese Internet Cafes Will Reach 115K in 2007]. June 21, 2005. http://tech.sina.com.cn/i/2005-0621/1546641983.shtml.

Jiang, Qiaolei, and Louis Leung. "Internet Addiction." In The Internet in China: An Encyclopaedic Handbook of Online Business, Information Distribution, and Social Connectivity, edited by Ashley Esarey, et al., 30-237. Great Barrington, Mass.: Berkshire Publishing, 2015.

Jin, Dal Yong. "Digital Platform as a Double-edged Sword: How to Interpret Cultural Flows in the Platform Era." International Journal of Communication 11 (2017): 3880-98.

Jin, Dal Yong. Digital Platforms, Imperialism and Political Culture. London: Routledge, 2015.

Jin, Dal Yong. Korea's Online Gaming Empire. Cambridge: MIT Press, 2010.

Jin, Dal Yong. "The Digital Korean Wave: Local Online Gaming Goes Global." Media International Australia, 141 (2011): 128-36.

Jin, Dal Yong. Korea's Online Gaming Empire. Cambridge: MIT Press, 2010.Jin, Dal Yong, and Florence Chee. "Age of New Media Empires: A Critical Interpretation of the Korean Online Game Industry." Games and Culture, 3, no. 1, (2008): 38-58.

Keane, Michael. Created in China: The Great New Leap Forward. London: Routledge, 2007.

Liboriussen, Bjarke. "Amateur Gold Farming in China: 'Chinese Ingenuity', Independence, and Critique." Games and Culture, 11, no. 3, (2016): 316-31.

Liu, Chun. "Raising the Golden Goose: A Retrospective Analysis of the State's Role in China's Online Game Industry." Media International Australia, 149 (2013): 41-54.

Lu, Zhouxiang. "From E-Heroin to E-Sports: The Development of Competitive Gaming in China." The International Journal of the History of Sport 33, no. 18, (2017): 2186-206.

McDonald, Anna. "The Global Games Market Will Reach \$108.9 Billion in 2017 with Mobile Taking 42\%." Newzoo, April 20, 2017. https://newzoo.com/insights/articles/theglobal-games-market-will-reach-108-9-billion-in-2017-with-mobile-taking-42/.

McLelland, Mark, Haiqing Yu, and Gerard Goggin. "Alternative Histories of Social Media in Japan and China." In Sage Handbook on Social Media, edited by Jean Burgess, Alice Marwick, and Thomas Poell, 53-68. Thousand Oaks, CA: SAGE, 2017. 
Ministry of Culture of PRC. "2012 nian Zhonggo wangba shichang niandu baogao zhaoyao" [Extract of 2012 Annual Report on Chinese Internet Cafes Market]. April 27, 2013. http://www.mcprc.gov.cn/whzx/bnsjdt/whscs/201304/t20130427_346183.html.

Rifkin, Jeremy. The Third Industrial Revolution. New York: Palgrave Macmillan, 2011.

Srnicek, Nick. Platform Capitalism. London: Polity Press, 2017.

Su, Wendy. "A Brave New World?-Understanding U.S.-China Coproductions: Collaboration, Conflicts and Obstacles." Critical Studies in Media Communication 34 (2017): 480-94. doi:10.1080/15295036.2017.1349326.

Szablewicz, Marcella. "A Realm of Mere Representation? 'Live' E-Sports Spectacles and the Crafting of China's Digital Gaming Image." Games and Culture 11 (2016): 256-74.

Tarantola, Andrew. "Chinese Internet Giant Tencent Is Building an eSports Park." May 16, 2017. https://www.engadget.com/2017/05/16/chinese-internet-giant-tencent-isbuilding-an-esports-park/.

Taylor, T. L. Raising the Stakes: E-Sports and the Professionalization of Computer Gaming. Cambridge: MIT Press, 2012.

Technode. "Chinese Video Giants Are Becoming Production Powerhouses." October 13, 2017. http://technode.com/2017/10/13/chinese-video-giant-production-powerhouses/.

Thornhill, John. "China's Digital Economy Is a Global Trailblazer." Financial Times, March 21, 2017. https://www.ft.com/content/86cbda82-0d55-11e7-b030-768954394623? $\mathrm{mhq} 5 \mathrm{j}=\mathrm{e} 7$.

Wang, Junjie. "With 50 Million Daily Active Users and 200 Million Registered Users, Why Is the Honor of Kings So Popular?" [5000 wan ri huoyue yonghu, 2 yi xiazai liang, wangzhe rongyao weishenmo hui zhemo huo]. IT Times, March 6, 2017. http://www .itxinwen.com/news/news_13893.shtml.

Wangyi. "2016 nian wangba shuliang ji shichang hangqing fenxi" [Market Analysis of the Internet Cafes and Market in 2016]. 2017. http://www.dnzmkg.com/news / hydt/2017-06-08/289.html.

Wei, Lu, and Wen Chen. "Internet Cafés." In The Internet in China: An Encyclopaedic Handbook of Online Business, Information Distribution, and Social Connectivity, edited by Ashley Esarey et al., 204-10. Great Barrington, Mass.: Berkshire Publishing, 2015.

Woetzel, Jonathan et al. "China's Digital Economy: A Leading Global Force." McKinsey Report, 2017. https://www.mckinsey.com/global-themes/china/chinas-digital-economya-leading-global-force.

Yee, Nick. "Yi-Shan-Guan." 2006. http://www.nickyee.com/daedalus/archives/001493.php.

Yoon, Sung-won. "Eyedentity Seeks to Boost Global e-sports Business." The Korea Times, July 19, 2017, http://www.koreatimes.co.kr/www/news/tech/2017/07/134_233300 .html.

Zheng, Bijian. China's Road to Peaceful Rise. Translated by Sun Miaoyi and Shi Yanhua. Abingdon: Routledge, 2011. 